\title{
The added value of Bayesian inference for estimating biotransformation rates of organic contaminants in aquatic invertebrates
}

\author{
Aude Ratier ${ }^{\mathrm{a}, \mathrm{b}}$, Christelle Lopes ${ }^{\mathrm{b},{ }^{*}}$, Olivier Geffard ${ }^{\mathrm{a}}$, \\ Marc Babut ${ }^{\mathrm{a}}$. \\ a INRAE, RiverLy, Ecotoxicology Laboratory, 5 Avenue de la Doua, CS20244, 69625 \\ Villeurbanne Cedex, France. \\ b Univ Lyon, Université Lyon 1, CNRS, Laboratoire de Biométrie et Biologie Evolutive \\ UMR5558, 69622 Villeurbanne, France. \\ * Corresponding author: christelle.lopes@univ-lyon1.fr
}

\section{Role of the funding source}

This study was part of Aude RATIER's PhD project. French Agency for Biodiversity provided support for the research project, and Irstea provided Aude RATIER's wages. The present study had no specific funding. The French Agency for Biodiversity was not involved in the design of the model, data processing, writing the report, or the decision to submit for publication.

\section{Abstract}

Toxicokinetic (TK) models refer to the process of contaminant bioaccumulation as a balance between rate of uptake from different sources (e.g. water or food), and rate of elimination via different processes such as excretion, growth and/or biotransformation. Biotransformation can considerably modify the fate of chemicals in an organism, especially their bioavailability, residence time, and toxicity. Invertebrate models generally neglect this process as they assume a low metabolic activity. However, some species such as Gammarus sp. amphipods are able to metabolize a vast range of organic compounds. Some recent TK models include biotransformation, but they prove limited for estimating related parameters by giving negative values and/or large uncertainties for biotransformation rate(s). Here we propose a generic TK model accounting for biotransformation using a Bayesian framework for simultaneously estimating the parameters. We illustrated the added value of our method by fitting this generic TK model to 22 published datasets of several benthic invertebrate species exposed to different chemicals. All parameters are estimated simultaneously for all datasets and showed narrow estimates. Furthermore, the median model predictions and their $95 \%$ credibility intervals showed that the model confidently fitted the data. In most cases the uncertainties around biotransformation rate(s) were reduced in comparison to the original studies. From a methodology standpoint, this paper reflects 
1 that Bayesian inference has real added value for simultaneously estimating all TK 2 parameters for parent chemicals and their metabolite(s) based on all available data, 3 while accounting for different types of data and the correlation between parameters. 4 Bayesian inference was able to overcome the limits of previous methods, since no 5 parameters were fixed and no irrelevant negative values were obtained. Moreover, the $695 \%$ credibility intervals around model predictions, which are core uncertainties for 7 Environmental Risk Assessment, were easily acquired.

9 Keywords: Invertebrate - Biotransformation - Bayesian inference - Toxicokinetic 10 model - Bioaccumulation

12 Highlights:

13 - A Bayesian framework was developed for a TK model considering biotransformation 14 - It was applied to Chironomus, Gammarus, Hyalella, Nereis and Lumbriculus genus

15 - It was applied to various chemicals (PAHs, drugs and plant protection products)

16 - In ERA, quantification of uncertainties around model predictions are crucial

17 - For metabolites, uncertainties around parameters were reduced 


\section{Introduction}

Biotransformation of chemicals can significantly modify the fate of chemicals in an organism, especially their bioavailability, toxicity, and residence time in the environment (e.g. water, sediment) and/or in an organism (Livingstone 1998). A chemical compound has to enter the organism to have effect, so biotransformation means that it accumulates less target chemical (parent compound) compared to untransformed chemical. Firm knowledge of the major quantitative and qualitative resemblances and dissimilarities in biotransformation pathways between species is a critically-needed foundation for designing toxicity tests, developing biomarkers, modeling chemical fate in ecosystems, and understanding the selective part of biotransformation in animal ecology and evolution (Livingstone 1994).

Directive 2008/105/EC, the Environmental Quality Standards Directive, defines the good chemical status to be achieved by all Member States from Europe and, together with Water Framework Directive 2000/60/EC, lays down the legal basis for monitoring of priority substances in sediment and biota. For several substances of the listed priority substances and certain other pollutants included in the Directive, the establishment of Community level Environmental Quality Standards (EQS) is limited to parent compound concentrations in biota, and fails to consider metabolites and their potential toxic effects on the organism.

Substantial progress has been made in measuring metabolites and estimating biotransformation rates for organic chemicals in fish (Arnot et al. 2008a, Arnot et al. 2008b, Nichols et al. 2007) and, to a lesser extent, in other aquatic organisms (Katagi, 2010). Biotransformation by aquatic invertebrates has often been supposed to be limited compared to fish (Morrison et al. 1996), as invertebrates are thought to have low metabolic activity. Nonetheless, researches conducted during the past decade have shown that several invertebrate species are able to metabolize various chemicals (Ashauer et al. 2012, Fu et al. 2018, Jeon et al. 2013, Miller et al. 2017, Rösch et al. 2016). For example, metabolites were quantitatively measured in Daphnia magna and Gammarus fossarum exposed to drugs and plant protection products (Jeon et al. 2013).

In Environmental Risk Assessment (ERA), models based on toxicokinetic (TK) are commonly used to predict contaminant concentrations in organisms from those to which they are exposed in their environment (EPA 2006). For aquatic invertebrates, compartmental models are often used, where the organism is considered as a single compartment. In TK models, biotransformation could be considered as part of total elimination (MacKay and Fraser 2000): the biotransformation rate points out how much biotransformation contributes to the reduction of parent compound bioaccumulation. Van der Linde et al. (2001) contended that including the biotransformation term in TK models could correct the overestimation of internal concentrations, even in the absence of experimental data for metabolites. They proposed a "difference method" to estimate biotransformation rate by considering it as the difference between the global elimination rate and the sum of the rates for other dissipation processes (growth dilution, excretion). Arnot et al. (2008b) further developed a similar approach for nonionic organic chemicals, where biotransformation rate constants were calculated as the difference between a measured bioconcentration factor or elimination rate constant, and a model-derived bioconcentration factor or elimination rate constant estimated assuming no biotransformation. Chen and Kuo (2018) also estimated biotransformation rates from whole-body biotransformation half-lives, which were 
estimated on the basis of free dissolved chemical fraction. However, these approaches present drawbacks, chiefly that they lead to large uncertainties around biotransformation rates and in some cases have even yielded negative values.

Estimating biotransformation rates in invertebrate species by fitting a TK model to experimental data gained further appeal with a study by Ashauer et al. (2012), who used bioaccumulation kinetics of 11 xenobiotics and their metabolites in Gammarus pulex. They constrained the parameters to positive values and estimated them by least-squares minimization without weighting data. Apart from two compounds where the uptake rate from water needed to be kept fixed, all parameters were estimated simultaneously. Also, the elimination rate of the parent compound reached its lower boundary zero for five chemicals, large confidence intervals were obtained for the uptake and elimination rates of three compounds, and uncertainties around mean predictions were missing. More reliable risk assessment hinges on properly estimating parameters with their uncertainties and considering their between-parameters correlation. Finally, Kuo and Chen (2016) proposed a generic theoretical framework allowing to estimate biotransformation rates from kinetic observations of the parent contaminant and its metabolites. Their framework was applied to two polychaetes (Nereis diversicolor and Tubifex tubifex) and the oligochaete Lumbriculus variegatus using data for two chemicals, i.e. pyrene and 2,4,6-trinitrotoluene, and parameters were estimated by least-squares minimization of errors. The parent-compound parameters were either fixed to the values reported in the original studies, or estimated with the best fit obtained, and then fixed to estimate only two parameters, i.e. metabolite biotransformation rate and metabolite elimination rate. Their method could be readily incorporated into standard experimental protocols. However, as all illustrations in their research dedicated to worm species, further validations across diverse biological species would be suitable, especially for the main species studied in bioaccumulation studies (fish and invertebrates). Furthermore, they only considered the simplest case of constant exposure level and they applied the model only to the uptake phase, neglecting the elimination phase. A step forward would be to revisit the existing biotransformation literature with their approach on well-studied organic contaminants such as polycyclic aromatic hydrocarbons (PAHs) and on chemicals of growing environmental concern.

As biotransformation depends on biological pathways of the organism and the mode of action of the chemical, TK models must adapt to the specie and to the chemical considered to include the biotransformation process. Thus, this study introduces a unified Bayesian inference framework to estimate parameters of TK models accounting for biotransformation processes. This approach is based on simultaneously estimating all kinetic parameters from accumulation and depuration data for the parent compound and its metabolite(s). In total, 22 experimental datasets from the literature encompassing six invertebrate aquatic species commonly used in ERA (i.e. Gammarus pulex, Gammarus setosus, Chironomus tentans, Hyalella azteca Nereis diversicolor, and Lumbriculus variegatus) exposed to 17 chemicals from water and/or diet. TK models were fitted on each couple chemical-species. We recommend the Bayesian approach because it allows to estimate TK parameters without constraining or fixing the values, while accounting for the correlations between parameters. This approach also provides an accurate assessment of the uncertainty around parameters estimates and model predictions. 


\section{Material and methods}

\subsection{A generic TK model accounting for biotransformation}

A generic first-order TK model can be written as follows (Eqs. (1) and (2), Ratier et al. (2019)):

$$
\left\{\begin{array}{l}
\frac{d C(t)}{d t}=\sum_{i=1}^{n}\left(k_{i} \times C_{i}(t)\right)-\sum_{j=1}^{p}\left(k_{j} \times C(t)\right) \text { for } 0 \leq t \leq t_{c} \\
\frac{d C(t)}{d t}=-\sum_{j=1}^{p}\left(k_{j} \times C(t)\right) \text { for } t>t_{c}
\end{array}\right.
$$

where $C(t)$ is contaminant concentration at time $t$ (days) in the whole organism (ng gorg${ }^{1}$ or nmol $\mathrm{kgorg}^{-1}$ where mass is expressed in wet weight $(\mathrm{ww})$ ), $k_{i}$ is uptake rate from the contamination source $i\left(\right.$ day $\left.^{-1}\right), C_{i}(t)$ is contaminant concentration (like $C(t)$, i.e. in $\mathrm{ng} \mathrm{ml}^{-1}$ if $C(t)$ in $\mathrm{ng} \mathrm{g}^{-1}$ ) in the contamination source $i$ at time $t$ (day), $n$ is number of exposure sources, $k_{j}$ is the rate for the elimination process $j\left(\right.$ day $\left.^{-1}\right), p$ is number of elimination routes and the parameter $t_{c}$ corresponds to the duration of the accumulation phase (days). In classical bioaccumulation experiments, this accumulation phase (Eq. (1)) is generally followed by a depuration phase where organisms are placed in clean (contaminant-free) medium. Eq. (2) thus corresponds to this depuration phase, in which only elimination processes take place.

Biotransformation is included as an elimination route $\left(k_{j}\right)$ for the parent compound, and the specific biotransformation rate is noted $k_{m}$. Thus, Eq. (1) and (2) could be rewritten for the parent compound as follows (Eqs. (3) and (4)), by distinguishing biotransformation from other elimination processes:

$$
\left\{\begin{array}{l}
\frac{d C(t)}{d t}=\sum_{i=1}^{n}\left(k_{i} \times C_{i}(t)\right)-\sum_{d=1}^{q}\left(k_{d} \times C(t)\right)-\sum_{x=1}^{z}\left(k_{m, x} \times C(t)\right) \text { for } 0 \leq t \leq t_{c} \\
\frac{d C(t)}{d t}=-\sum_{d=1}^{q}\left(k_{d} \times C(t)\right)-\sum_{x=1}^{z}\left(k_{m, x} \times C(t)\right) \quad \text { for } t>t_{c}
\end{array}\right.
$$

where $k_{d}$ is the rate associated to elimination process $d$ other than biotransformation, $q$ is the number of elimination process other than biotransformation, $k_{m, x}$ is the biotransformation rate of a metabolite $x\left(\right.$ day $\left.^{-1}\right)$ and $z$ is number of metabolites.

These equations depicting the bioaccumulation and depuration of the parent compound should then be coupled with the equation concerning the corresponding metabolite(s) (Eq. (5):

$$
\frac{d C_{m e t, x}(t)}{d t}=\sum_{x=1}^{z}\left(k_{m, x} \times C(t)\right)-\sum_{x=1}^{z}\left(k_{\text {emet }, x} \times C_{m e t, x}(t)\right)
$$

where $C_{m e t, x}(t)$ is the concentration of metabolite $x$ at time $t$ (days) in the whole organism ( $\mathrm{ng} \mathrm{g}^{-1}$ or nmol kg-1 $\mathrm{ww}$ ) and $k_{\text {emet, } x}$ is elimination rate of metabolite $x\left(\right.$ day $\left.^{-1}\right)$. 
The model is adapted to the contamination-source data, i.e. water or sediment. We supposed that (i) metabolites come exclusively from the parent compound, (ii) they are not reuptaken, (iii) they are eliminable and (iv) the concentration of parent compound is constant over time in media. Analytical solutions are provided for the parent compound and for its metabolites for both the uptake and elimination phases (Annex S1).

\subsection{Datasets from the literature and associated inference methods}

In literature, we found seven studies reporting biotransformation kinetics in aquatic invertebrates of 22 parent compounds, including PAHs, drugs and plant protection products (Giessing et al. 2003, Schuler et al. 2003, Mäenpää et al. 2009, Ashauer et al. 2012, Carrasco-Navarro et al. 2015, Miller et al. 2017, Fu et al. 2018). In each case, the generic model (Eqs (3-4) and (5-6) was adapted to these biotransformation TK data. For all the datasets, only one exposure route was considered, i.e. by sediment or by water according to the study (Table 1). A single metabolite was often followed (Giessing et al. 2003, Schuler et al. 2003, Mäenpää et al. 2009, Ashauer et al. 2012, Carrasco-Navarro et al. 2015, Miller et al. 2017), but two or three metabolites were followed during the tests in a few studies (Ashauer et al. 2012, Miller et al. 2017, Fu et al. 2018) (Table 1). Only experimental data were reported in one study (Giessing et al. 2003) whereas the others estimated parameters of the TK model for parent compounds, and, less often, for the metabolite (Ashauer et al. 2012, Carrasco-Navarro et al. 2015, Fu et al. 2018).

Briefly, Miller et al. (2017) exposed for two days Gammarus pulex to propranolol and diazepam spiked water. The uptake rate constant $\left(k_{w}\right)$ and elimination rate constant $\left(k_{e}\right)$ were obtained using a curve fitting algorithm, using either the simultaneous or sequential modelling methods.

For 24 hours, Ashauer et al. (2012) exposed Gammarus pulex to water spiked with 2,4-dichloroaniline, 2,4-dichlorophenol, 2,4,5-trichlorophenol, 4-nitrobenzylchloride, aldicarb, carbaryl, carbofuran, chlorpyrifos, malathion, pentachlorophenol and seanine. They constrained the parameters to positive values. They were obtained without weighting of data by least-squares minimization (Levenberg-Marquardt algorithm). Asymptotic standard errors of parameters were obtained from the covariance matrix and by calculation of confidence intervals. Except for 4-nitro-benzylchloride and carbaryl where the uptake rate from water $\left(\mathrm{k}_{\mathrm{w}}\right)$ needed to be kept fixed at the value from a previous study (Ashauer et al. 2010) in order to reach a good fit, all parameters, for a given compound, were estimated simultaneously.

Carrasco-Navarro et al. (2015) exposed for four days Gammarus setosus to pyrene spiked water. In order to estimate the initial values of the parameters before running the inference process, they selected a model to fit the data into the Sigma Plot library. Then, a TK model was used to fit experimental data of total body burden, the parent pyrene concentrations, and the sum of all metabolites. The TK parameters were estimated by a least-squares fit.

Schuler et al. (2003) exposed Lumbriculus variegatus and Chironomus tentans to benzo(a)pyrene spiked sediment for 10 and 3 days, respectively. TK parameters were estimated by a two-step procedure: first, assuming that elimination can be neglected during the initial segment of the uptake phase, uptake rate from sediment $\left(k_{s}\right)$ was obtained from the uptake phase. Second, an iterative least-squares method was used to estimate the other parameters when the models were fitted to data. 
Mäenpää et al. (2009) exposed Lumbriculus variegatus to pyrene spiked water for 15 days. Their experiment was limited to the uptake phase. The TK model was fitted to the pyrene concentration in the test organisms, where only parent compound parameters were estimated by nonlinear regression. Relative parameters to metabolite were not estimated since only the experimental metabolite concentrations in organisms were given.

Giessing et al. (2003) exposed Nereis diversicolor to pyrene-spiked sediment for 9 days. Only the experimental concentrations of pyrene and its metabolite in organisms were reported. Parameters were not estimated.

Fu et al. (2018) exposed for 24 hours Hyalella azteca and Gammarus pulex to water spiked with azoxystrobin and prochloraz. They made a distinction among the parent compounds, the sum of all measured primary metabolites which come directly from the parent compound, and of the total of all secondary metabolites. To estimate the parameters, they contrast two approaches: stepwise fitting (by fixing the uptake rate to estimate the other parameters, where a greater significance was attributed to the uptake rate from water, $k_{w}$ ) and simultaneously (constrained to positive values). Comparable results were achieved for both approaches.

In summary, we selected these 22 datasets to consider several invertebrates species (polychaetes, oligochaetes, diptera and amphipods) encompassing different ways of life (epibenthic and endobenthic), exposed via spiked water or sediment to various chemicals (17 compounds including two PAHs, two drugs, 10 plant protection products and three precursors in their synthesis) with different properties (low to high hydrophobicity, logKow between 1.13 and 6.13), with variable numbers of metabolites, and contrasting approaches to estimate the parameters. 
1 Table 1. Summary of the chosen literature data where biotransformation kinetics in 2 invertebrates are reported.

\begin{tabular}{|c|c|c|c|c|}
\hline Species & Reference & Chemicals & $\begin{array}{l}\text { Exposure } \\
\text { route }\end{array}$ & $\begin{array}{c}\text { TK parameters } \\
\text { availability }\end{array}$ \\
\hline \multirow{4}{*}{ 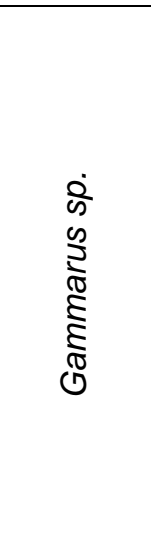 } & $\begin{array}{l}\text { Miller et al., } \\
\quad 2017\end{array}$ & Propranolol & water & $\begin{array}{l}\text { Incomplete }\left(\mathrm{k}_{\mathrm{m}}\right. \\
\text { and kemet were } \\
\text { missing) }\end{array}$ \\
\hline & $\begin{array}{l}\text { Fu et al., } \\
2018^{*}\end{array}$ & $\begin{array}{l}\text { Azoxystrobin } \\
\text { Prochloraz }\end{array}$ & water & All \\
\hline & $\begin{array}{c}\text { Ashauer et al., } \\
2012\end{array}$ & $\begin{array}{c}\text { Aldicarb } \\
\text { Carbaryl } \\
\text { Carbofuran } \\
\text { Malathion } \\
\text { Pentachlorophenol }\end{array}$ & water & All \\
\hline & $\begin{array}{c}\text { Carrasco- } \\
\text { Navarro et al., } \\
2015 \\
\end{array}$ & Pyrene & water & All \\
\hline
\end{tabular}

\begin{tabular}{|c|c|c|c|c|c|}
\hline 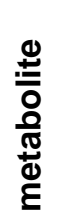 & 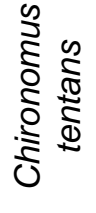 & $\begin{array}{l}\text { Schuler et al., } \\
2003\end{array}$ & Benzo(a)pyrene & sediment & $\begin{array}{l}\text { Incomplete } \\
\text { (Kemet is } \\
\text { missing) }\end{array}$ \\
\hline$r$ & \multirow{2}{*}{ 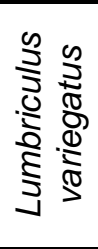 } & $\begin{array}{l}\text { Schuler et al., } \\
2003\end{array}$ & Benzo(a)pyrene & sediment & $\begin{array}{c}\text { Incomplete } \\
\text { (Kemet is } \\
\text { missing) }\end{array}$ \\
\hline & & $\begin{array}{l}\text { Mäenpää et } \\
\text { al., } 2009\end{array}$ & Pyrene & water & $\begin{array}{c}\text { Incomplete ( } \mathrm{km} \\
\text { and kemet are } \\
\text { missing) }\end{array}$ \\
\hline & 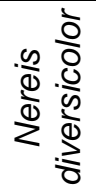 & $\begin{array}{l}\text { Giessing et al., } \\
2003\end{array}$ & Pyrene & sediment & None \\
\hline & 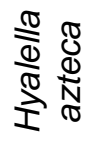 & $\begin{array}{l}\text { Fu et al., } \\
2018^{*}\end{array}$ & $\begin{array}{l}\text { Azoxystrobin } \\
\text { Prochloraz }\end{array}$ & water & All \\
\hline 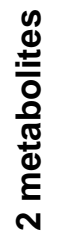 & 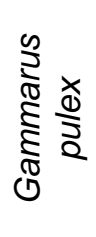 & $\begin{array}{c}\text { Ashauer et al., } \\
2012\end{array}$ & $\begin{array}{c}\text { Chlorpyrifos } \\
\text { 2,4-dichloroaniline } \\
\text { 2,4-dichlorophenol } \\
\text { 2,4,5-trichlorophenol }\end{array}$ & water & All \\
\hline 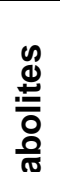 & $\frac{\sqrt{n}}{0}$ & $\begin{array}{c}\text { Ashauer et al., } \\
2012\end{array}$ & $\begin{array}{c}\text { Seanine } \\
\text { 4-nitrobenzyl-chloride }\end{array}$ & water & $\begin{array}{c}\text { All } \\
\text { (kw fixed for 4- } \\
\text { nitrobenzyl- } \\
\text { chloride) }\end{array}$ \\
\hline$\stackrel{\mathscr{E}}{\text { m }}$ & $\underset{\mathbb{\sigma}}{\stackrel{\Sigma}{\sigma}}$ & $\begin{array}{l}\text { Miller et al., } \\
2017\end{array}$ & Diazepam & water & $\begin{array}{l}\text { Incomplete }\left(\mathrm{k}_{\mathrm{m}}\right. \\
\text { was missing) }\end{array}$ \\
\hline
\end{tabular}

*: The second metabolite originated from first metabolites were not considered. 


\subsection{Bayesian inference framework}

\subsubsection{The TK model(s)}

Considering only one exposure pathway (water or sediment depending on the data) and in accordance with the number of metabolites, Eqs. (3) and (5) can thus be adapted for a parent compound and its metabolites (Eq. (6) for the uptake phase and Eq. (7) for the elimination phase), for each species/chemical couple applied separately:

(1)

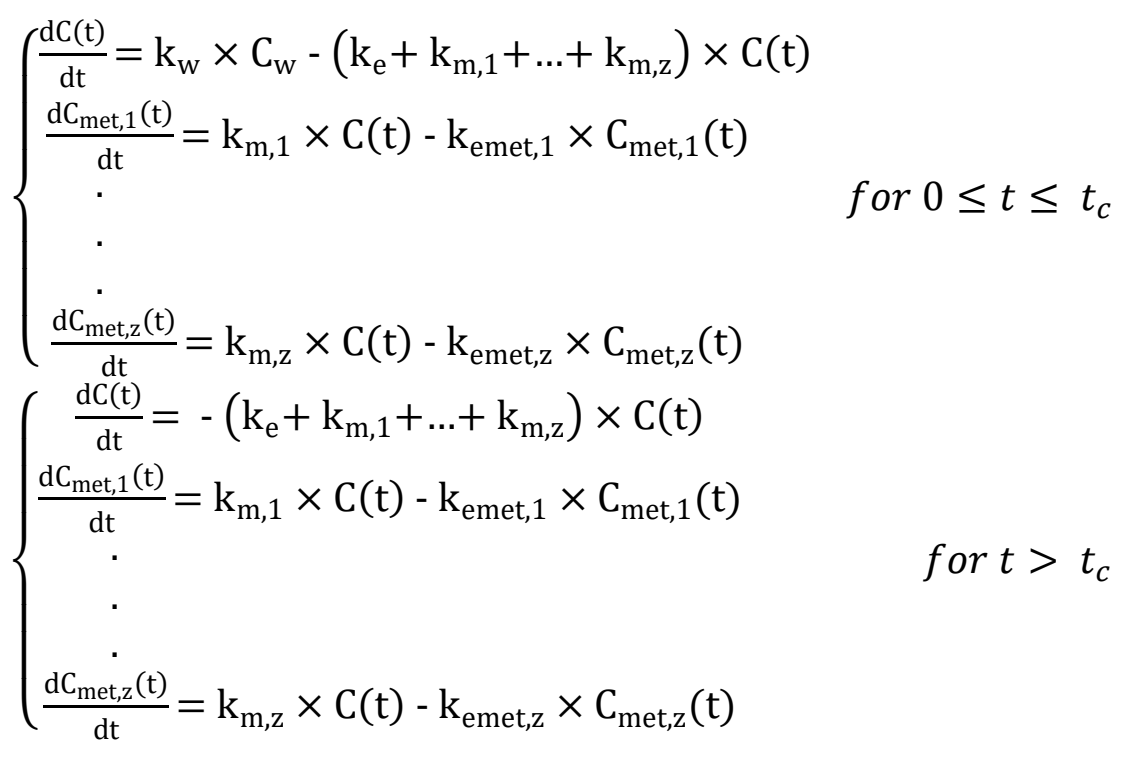

where $C_{w}$ (or $C_{s}$ ) is parent-compound concentration in water (or sediment) ( $\mu \mathrm{mol} \mathrm{L}^{-1}$, $\mathrm{nmol} \mathrm{L}-1, \mu \mathrm{g} \mathrm{mL}^{-1}, \mu \mathrm{g} \mathrm{L}^{-1}$ or $\mathrm{ng} \mathrm{gsed}^{-1}$ ), $k_{w}\left(\right.$ or $k_{s}$ ) is the uptake rate from water (or from sediment) of the parent compound $\left(\right.$ day $\left.^{-1}\right), k_{m, x}$ is biotransformation rate of the parent compound to the metabolite, $C_{m e t, x}($ for $x=1 \ldots z)$ is concentration of the metabolite $x$ and $k_{\text {emet, } x}$ is elimination rate of metabolite $x$. In the datasets used, we have data for one, two or three metabolites $(z=1,2$ or 3$)$.

\subsubsection{Stochasticity}

For the contaminant concentration accumulating in the organism (parent or metabolite), we supposed a Gaussian distribution (Eq. (8) or (9)):

$$
\begin{aligned}
& C_{o b s}(t) \sim N(C(t), \sigma) \\
& C_{o b s, \text { met }, \mathrm{x}}(t) \sim N\left(C_{\text {met }, x}(t), \sigma_{\text {met }, x}\right)
\end{aligned}
$$

where $N$ stands for normal distribution, $C_{o b s}(t)$ corresponds to the chemical concentration in the organism at time $t$ measured during the experiments, $C_{o b s, m e t, x}(t)$ is concentration of metabolite $x$ in the organism at time $t$ measured during the experiments, $C(t)$ is concentration of contaminant in the organism at time $t$ predicted by the model (Eqs. (6) and (7)), $C_{m e t, x}(t)$ is concentration of metabolite $x$ in the organism at time $t$ predicted by the model (Eqs. (6) and (7)), $\sigma$ is the standard deviation of the concentration contaminant in the organism, and $\sigma_{m e t, x}$ is the standard deviation of the concentration of metabolite $x$ in the organism.

In Figure S1, the generic directed acyclic graph (DAG) for an organism exposed to a parent compound and its metabolite(s) is given. 
The prior distributions of the parameters are summarized in Table S1. They were defined as non-informative uniform decimal logarithm $(-5,2)$ distributions, except where previous studies had already estimated a parameter or reported available data: in this case, we can assume a normal prior distribution with the estimated mean value and the precision with a standard deviation (e.g. in the study of Ashauer et al., (2012)), in order to account for the possible differences in experimental conditions, at least twice the value estimated. For more details, when no previous data were available (other than the original study), a uniform distribution was assumed because general prior information was available: parameters could not be negative (for a biological meaning) and it is often noticed that TK parameters are ranging between 0.00001 and 100 . Thus, a uniform decimal logarithm $(-5,2)$ distribution was defined for most datasets. However, for some datasets, this distribution was not sufficient (i.e. when parameter estimated was closed to the limit, i.e. 0.00001 or 100). In this particular case, the prior distribution was enlarged until the estimated parameter was not too closed to the limit (Table S1). This was the case for malathion, 2,4,5-trichloro-phenol and 2,4-dichlorophenol datasets (for $\mathrm{ke}_{\mathrm{e}}$ ), chlorpyrifos, 2,4,5-trichloro-phenol and 2,4-dichloro-phenol (for $\mathrm{k}_{\mathrm{w}}$ ) and pyrene for $\mathrm{G}$. setosus and Nereis diversicolor (all parameters).

Priors were defined on the decimal logarithm scale in order to give the same probability to low or high values. As a non-informative $(0.001,0.001)$ Gamma prior on the precision is usually used for variance parameters (Lambert et al. 2005, Richards and Chaloupka 2009), we also assumed that prior distribution.

\subsubsection{MCMC simulations}

JAGS and $R$ software were used to perform inference computation (Plummer 2019, R Core Team 2020). Bayesian inference via Markov Chain Monte Carlo (MCMC) sampling was used to fit the models to data. For each dataset, in order to set the required thinning and number of iterations to reach an accurate estimation of each parameter, we ran a short sampling phase (a burn-in phase of 20,000 iterations, then 5,000 iterations) for three chains using the Raftery and Lewis (1992) method (Table S1). Furthermore, we used visual inspection as well as the Gelman criterion (Gelman, 1995) or Geweke criteria (Geweke 1989) to monitor the convergence of the three chains. The $R$ codes are available in supporting information (Annex S2). At the end, we kept between 500 and the 14,285 last iterations for each chain according to the data, meaning that the joint posterior distribution ranged between 1,500 to 42,857 sets of parameters, all simultaneously estimated and thus taking into account betweenparameter correlation.

\subsubsection{Parameter posterior distributions and model predictions}

From the joint posterior distribution, we deduced the marginal posterior distribution for each parameter, which can be summarized by the mean (or the median) and by the $95 \%$ credibility interval (quantiles of the distributions, in brackets). The accuracy of parameter estimation can be visualized by comparing prior and posterior distributions: the data bring enough information to precisely estimate parameters when a narrower posterior distribution is obtained than prior distribution. To check the relevance of model predictions, we plotted each dataset as the observed data superimposed over the mean model prediction (using the mean value obtained for each parameter) and the $95 \%$ credibility interval $(\mathrm{Cl})$. To obtain the $95 \% \mathrm{Cl}$, we ran a model simulation using the stochastic part (Eq. 8 and 9) with all the joint posterior distribution and then 
1 calculated the quantiles at $2.5 \%$ and $97.5 \%$ for each time step. Posterior Predictive 2 Checks (PPC) were also graphed in order to illustrate the goodness-of-fit. The PPC 3 plotted the observed data against the corresponding predicted value from the fitted 4 model as a $95 \%$-credible interval. If the fit is correct, then $95 \%$ of the observed values 5 are expected to fall inside credible intervals. Each dot corresponds to one observation 6 from the dataset, and the corresponding observed value can be read on the x-axis, 7 while the $y$-axis provides the value predicted by the fitted model as well as the $95 \%$ 8 credible interval. All these criteria came from the EFSA recommendations on TKTD 9 models (Ockleford et al., 2018).

A guidance is provided in supporting information (Annex S3) that gives the steps 12 for applying this framework to an experimental dataset. 


\section{Results}

\subsection{Parameter estimates and model predictions}

The inference process converged without constraining or fixing any parameter for all datasets. For each parameter, narrow posterior distributions were obtained, meaning that data provided enough information to accurately estimate parameters (Fig. S2). The mean value and $95 \% \mathrm{Cl}$ (in bracket) for each parameter and each species-contaminant pair are reported in Table S1.

The between-species differences in metabolic capacity were reported by the original studies. In the benzo(a)pyrene spiked sediment experiments (Schuler et al., 2003), chironomids had a better biotransformation capacity than L. variegatus $\left(k_{m, 1}=1.66\right.$ and $k_{m, 2}=0.038 \mathrm{~d}^{-1}$, respectively), as the authors had already denoted. In the work of Fu et al. (2018), comparable biotransformation rates were obtained for gammarid and hyalellid species exposed to prochloraz and azoxystrobin. Furthermore, for pyrene, $k_{m, 1}$ was higher in $G$. setosus and $L$. variegatus than $N$. diversicolor $\left(k_{m, 1}=1.04,1.54\right.$ and $0.0500 \mathrm{~d}^{-1}$, respectively), possibly due to the exposure route (sediment exposure for $N$. diversicolor) accordingly to the authors.

The highest $k_{m}$ values were obtained for organochlorine chemicals such as in G. pulex exposed to 2,4-dichlorophenol $\left(k_{m, 1}=39.5[13.0-93.5] \mathrm{d}^{-1}\right), 2,4,5$ trichlorophenol $\left(k_{m, 1}=38.2[3.11-93.8] \mathrm{d}^{-1}\right)$ and 4-nitrobenzyl-chloride $\left(k_{m, 1}=42.3\right.$ [30.858.5] and $k_{m, 2}=43.9$ [24.6-76.5] $\left.\mathrm{d}^{-1}\right)$. The lowest values were obtained for PAHs, such as $L$. variegatus exposed to benzo(a)pyrene $\left(k_{m, 1}=0.0380[0.0270-0.0480] \mathrm{d}^{-1}\right)$ and $N$. diversicolor exposed to pyrene $\left(k_{m, 1}=0.0500[0.0310-0.0730] \mathrm{d}^{-1}\right)$.

Model predictions generally showed good fit with experimental data for the parent compound but also for its metabolite(s) (Fig. 1 and S3), whatever the number of metabolites (from one to three, Fig. 1-a and 1-e), and even when only accumulation data were available, as for $L$. variegatus and $N$. diversicolor exposed to pyrene (Giessing et al. 2003, Mäenpää et al. 2009, Fig. 1-b and -c). However, model predictions showed an unsatisfying fit in the elimination phase of the parent compound for about half of the chemicals studied (propranolol, azoxystrobin (Fig. 1-d), chlorpyrifos, carbaryl, 2,4-dichlorophenol, malathion, pentachlorophenol, 4nitrobenzyl-chloride (Fig. 1-e), 2,4,5-trichlorophenol and seanine) and consequently underestimated the elimination rate. This result was also clearly visible on the respective PPCs (Fig. S4). 
mean model predictions

$95 \%$ credibility intervals

observed data for the parent compound

- observed data for metabolite 1

- observed data for metabolite 2

- observed data for metabolite 3
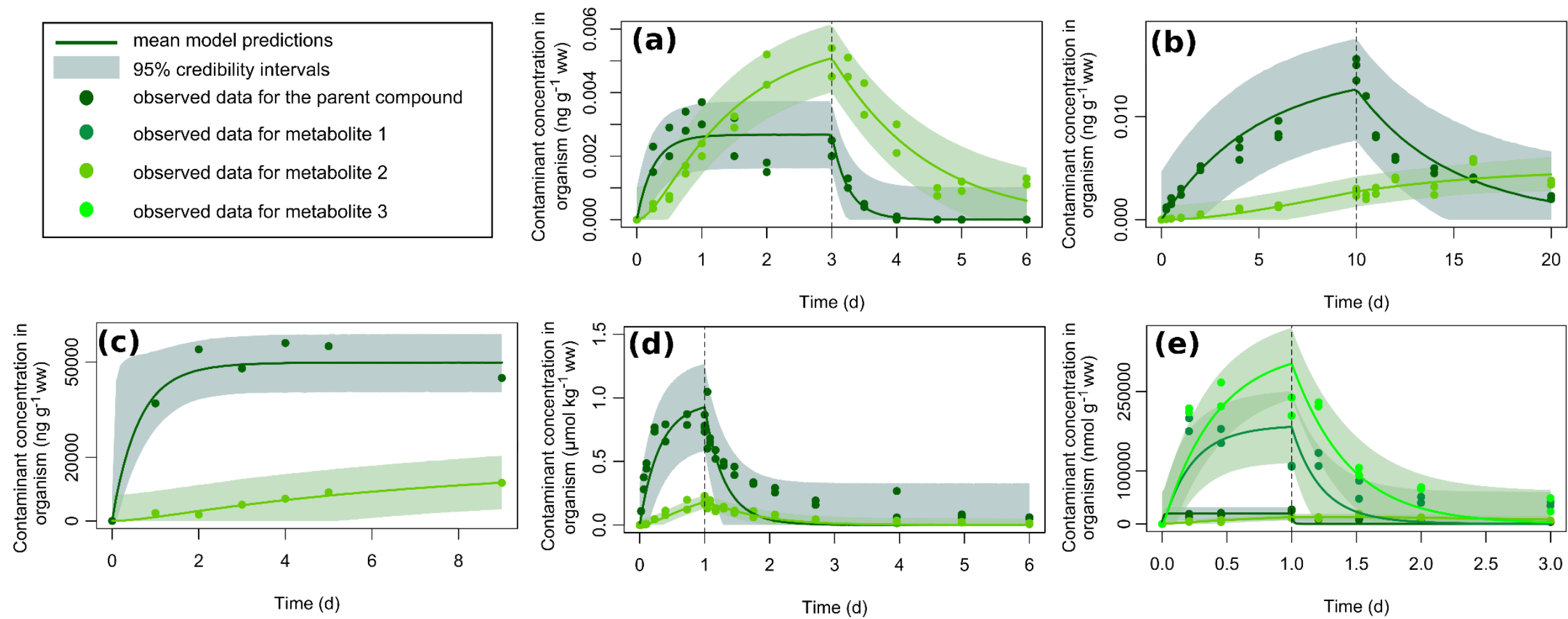

(plain line and gray area) for each parent compound and its metabolite(s) (Eqs. 6 to 9) plotted against time (days): (a) C. tentans exposed to benzo(a)pyrene (data from Schuler et al., 2003), (b) L. variegatus exposed to benzo(a)pyrene (data from Schuler et al., 2003), (c) N. diversicolor exposed to Pyrene (data from Giessing et al., 2003), (d) H. azteca exposed to Azoxystrobin (data from Fu et al., 2018) and (e) G. pulex exposed to 4-nitrobenzyl-chloride (data from Ashauer et al., 2012). The uptake and depuration phases are separated with the dashed vertical line. 
The $95 \% \mathrm{Cl}$ were added to the fits of predictions: the credibility band is relatively narrow, reflecting a relatively low variability, even if there were some cases where uncertainties around model predictions were wider (chlorpyrifos, malathion, 2,4,5trichlorophenol, propranolol, diazepam and pyrene).

\subsection{Comparison of parameter values and uncertainties between original estimations and those obtained by Bayesian inference}

When possible, a comparison was made between parameters values and their uncertainties obtained with our Bayesian inference method and the values and uncertainties given the in original publications. In particular, two studies (Ashauer et al. 2012, Fu et al. 2018) out of the seven chosen (i.e. 15 of the 22 datasets) had reported the mean estimated values for each parameter and their corresponding 95\% confidence intervals. Here we selected those with the most relevant results (Fig. 2).
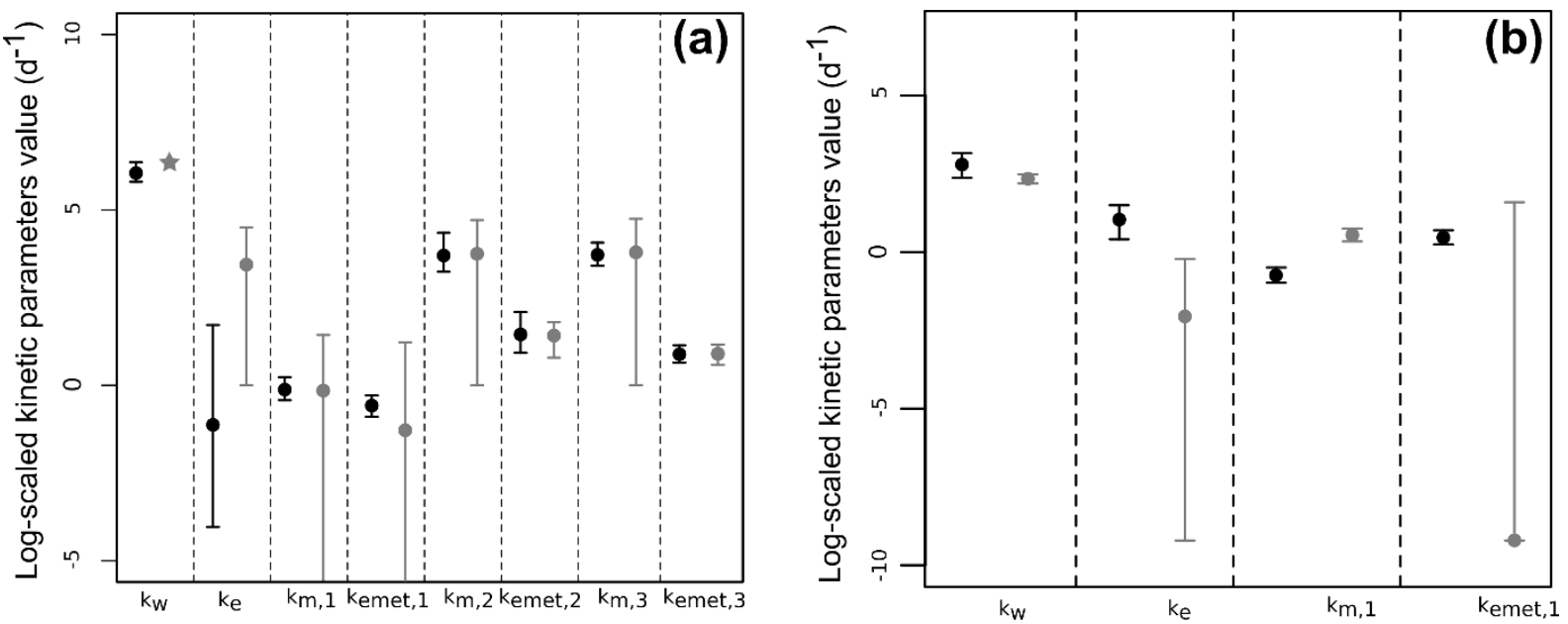

Figure 2. Log-scaled parameters $\left(d^{-1}\right)$ estimated by Bayesian inference (black) and by the original method (grey) for (a) G. pulex exposed to 4-nitrobenzyl-chloride (Ashauer et al., 2012), and (b) H. Azteca exposed to azoxystrobin (Fu et al., 2018). Dots represent mean values, stars represent fixed mean values of parameter and error bars report $95 \%$ credibility intervals (Bayesian inference) or confidence intervals (original studies).

When the uptake rates were fixed (carbaryl and 4-nitro-benzylchloride, Ashauer et al., 2012, Fig. 2-a), the uncertainty of the parameters correlated to those that had been fixed $\left(k_{w}\right)$ was necessarily underestimated in the original studies, which is why $\mathrm{Cl}$ around correlated parameters were wider with the Bayesian inference method. Indeed, for the carbaryl dataset (data not shown), $k_{w}$ and $k_{e}$ are highly correlated $\left(r^{2}=0.87\right)$ and the uncertainties for $k_{e}$ were larger than in the original study. In the case of 4-nitrobenzylchloride (Fig 2-a), $k_{w}$ and $k_{m, 2}$ are highly correlated $\left(r^{2}=0.81\right)$ and the uncertainties for $k_{m, 2}$ were larger than in the original study.

Otherwise, the mean $k_{m}$ values were similar between our Bayesian inference and the original methods in 19 out of 27 cases. For the 2,4,5-trichlorophenol, prochloraz 
1 and azoxystrobin (Fig. 2-b) datasets, the range of $k_{m}$ values was outside the confidence 2 interval of the original study. In addition, estimated values of parent-compound 3 parameters were sometimes outside of the confidence interval obtained in the original 4 study (chlorpyrifos, malathion, diazepam, prochloraz and azoxystrobin). As illustrated 5 in Figure 2-b for $H$. azteca exposed to azoxystrobin, the mean estimated $k_{m}$ was 0.47 $6 \quad[0.37-0.60] \mathrm{d}^{-1}$ with the Bayesian inference method against $1.8[1.4-2.1] \mathrm{d}^{-1}$ with the 7 original method. The two uncertainty intervals did not overlap (Fig. 2b). Moreover, the 8 mean estimated elimination rate was 2.88 [1.57-4.66] d $\mathrm{d}^{-1}$ in Bayesian inference against $90.13[0.0001-0.8] \mathrm{d}^{-1}$ with the original method. As observed for $k_{m}$, the two $k_{e}$ 10 uncertainty intervals did not overlap (Fig. 2b). 


\section{Discussion}

\subsection{Computational performance}

Here we propose using a Bayesian inference method to estimate the parameters of a generic TK model accounting for biotransformation. In previous work, we set out the various advantages of using Bayesian inference for modeling TK in freshwater benthic invertebrates (Ratier et al., 2019). In this paper, this approach was tested on data available for different species exposed to different contaminants, with either only bioaccumulation data, either bioaccumulation and depuration data, and with one or more metabolites.

There are three main limitations to estimating the parameters accounting for biotransformation in previous studies: ( $($ ) the need in some instances to fix one or more parameter values in order to estimate the others, (ii) outputs providing sometimes negative values for some parameters (e.g. km, Arnot et al., 2008a, 2008b) and (iii) missing uncertainties around mean model predictions. Bayesian inference overcomes these limits as we did not fix any parameters, we did not obtain negative values for $k_{m}$, and we were able to provide the $95 \%$ credibility intervals around model predictions in addition to correlations between parameters.

Uncertainties within environmental risk assessments need to be properly characterized in order to use risk estimates as a sound basis for informing risk management actions. In our modeling framework, we added the $95 \%$ credibility bands around model predictions. However, we did find large uncertainties around model predictions for some chemicals. Having larger uncertainties around parameters does not mean that the Bayesian inference process is less efficient than the one used in the original study. These large uncertainties could mainly be explained by incomplete experimental data. For example, it is possible that not all the metabolites were chemically analyzed and quantified. Furthermore, as suggested by Ashauer et al. (2012), the biotransformation pathways could be misunderstood: indeed, the model is not currently designed to consider metabolites derived from the products of parentcompounds biotransformation (phase II metabolites). This biotransformation pathway can be reasonably expected to decrease uncertainties as the process would be better described than when we hypothesized that all metabolites originated from the parent compound (larger uncertainties). It is therefore crucial to gain a better understanding of the biotransformation cascade mechanisms. Furthermore, analytical results may be more uncertain for metabolites than for parent compounds, due to the lack of standards; in which case the model fit would be accordingly less accurate. Another limitation with this kind of bioaccumulation tests is that they require a lot of measurements, and are time consuming and expensive.

\subsection{Applications}

TK models are used in ERA as the first step to evaluating the toxicity of a contaminant. They are developed to provide a theoretical framework for understanding exposure-uptake relationships and accumulation in organisms, testing hypotheses, and making predictions (e.g. predictions of the chemical concentration in organisms according to environmental concentration or vice versa). ERA of organic contaminants, and the ensuing regulatory guidelines for chemicals management and control have 
mostly been restrained to the bioaccumulation potential of the parent compounds (Kuo and Chen, 2016). However, there is legitimate concern over the failure to regulate for metabolites, which might have more effects than the parent compounds on organisms.

Some benthic organisms are able to metabolize and excrete benzo(a)pyrene (BaP) accumulated in their body (Schuler et al., 2003). However, some intermediates of BaP metabolism are highly toxic and highly mutagenic and/or carcinogenic (U.S. EPA., 2017). In France, the EQS biota defined for invertebrates exposed to PAHs is $5.00 \mathrm{ng} \mathrm{g}^{-1}$ ww (Directive 2008/105/EC). This value refers to BaP, which is deemed representing all PAHs.

Here we illustrate how to use TK models to retro-predict chemical concentrations in the sediment leading to the EQS biota. For this purpose, we first used experimental data from a published TK study on Chironomus tentans exposed to $\mathrm{BaP}$ spiked sediment (Schuler et al. 2003) to estimate the distributions of the model parameters and thus go on to predict the concentration in sediment that would lead to a concentration in biota below the corresponding $\mathrm{EQS}_{\text {biota }}$ for both $\mathrm{BaP}$ and its metabolites. We also spread the uncertainties around the median predictions. The results are reported on Figure 3 . The capacity of the chironomids to metabolize $\mathrm{BaP}$ is such that the metabolites alone achieve almost double the EQS biota concentration defined for the parent compound (Fig. 3-a). For the in-organism concentration of metabolites to meet EQS biota, the in-sediment concentration of $\mathrm{BaP}$ has to be two times lower (11.3 $\mathrm{ng} \mathrm{g}^{-1} \mathrm{dw}$, Fig. 3-b) than the predicted in-organism concentration for BaP only (23.5 $\mathrm{ng} \mathrm{g}^{-1} \mathrm{dw}$, Fig. 3-a). We also extended the exposure time (from 3 to 10 days) in order to reach the steady state for metabolite concentration in chironomids (Fig. 3b).
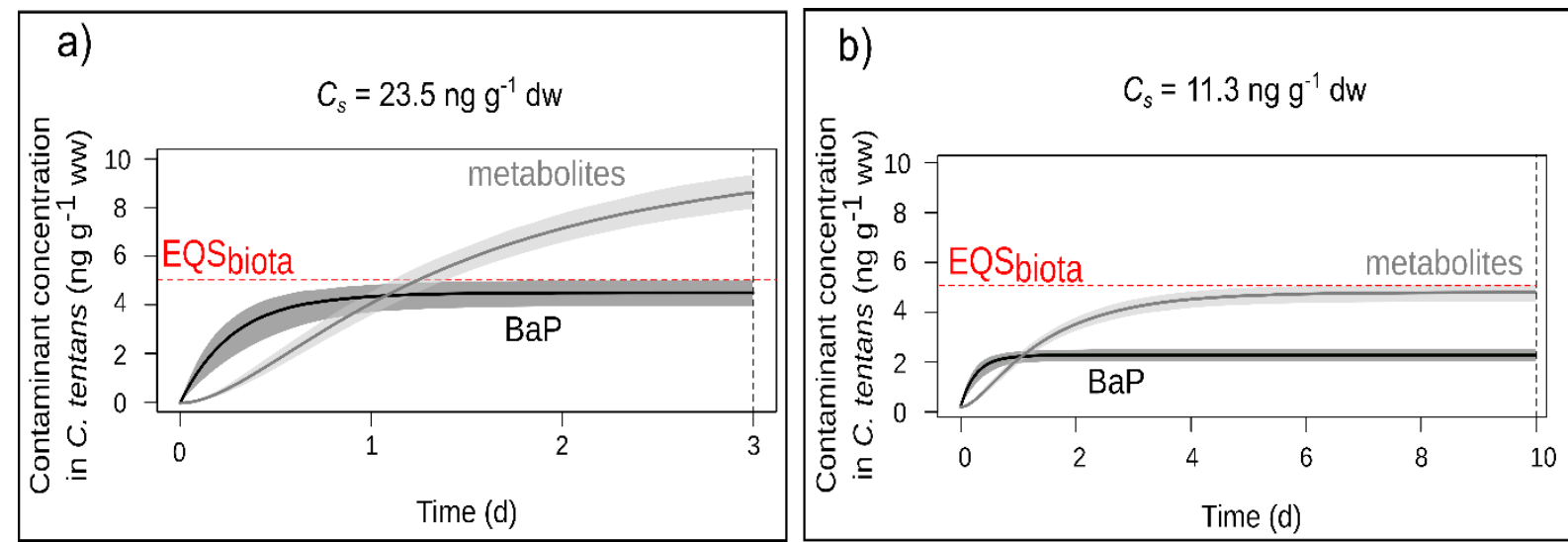

Figure 3. Predictions for $C$. tentans exposed to BaP spiked sediment (a) at $23.5 \mathrm{ng} \mathrm{g}$ ${ }^{1} \mathrm{dw}$ for 3 days and (b) at $11.3 \mathrm{ng} \mathrm{g}^{-1} \mathrm{dw}$ for 10 days. The EQS biota for BaP (5.00 $\mathrm{ng} \mathrm{g}^{-}$ $\left.{ }^{1} \mathrm{ww}\right)$ is represented by the red dashed horizontal line. metabolite concentrations in the organism could exceed the EQS biota defined for the parent compound. 


\section{Conclusions}

Here we proposed a unified inference framework to estimate kinetic parameters of a generic TK model, including biotransformation rates. A Bayesian framework was used to simultaneously estimated all parameters. This approach results in a quantification of the uncertainties around model predictions that play a key role in environmental risk assessment. A total of 22 aquatic invertebrate species-chemicals pairs were tested. The data encompassed different ranges of contaminants including pesticides, drugs and PAHs as well as various biological and ecological traits. Our framework also considers one to several metabolites. We successfully estimated the elimination parameters distinguishing excretion from biotransformation by applying the framework to several invertebrate species and chemicals. This approach is transferable to any species-chemicals pair, and it provides an accurate estimate of elimination rates by distinguishing the classical elimination rate from the biotransformation rate(s). The major added value of the Bayesian approach is to estimate simultaneously model parameter from different kinds of data. The predictions and their uncertainties around concentrations by the joint a posteriori distribution will also improve ERA, as illustrated in this study.

\section{Outlook}

We anticipate that Bayesian analysis can be used to simultaneously estimate parameters considering several exposure routes such as sediment and water. The model might be improved by integrating pulse exposures and secondary metabolite kinetics. Under laboratory conditions (e.g. OECD tests), and in most of the datasets available in the literature, the exposure concentration is usually held constant over time. However, the assumption of constant exposure concentration actually adds another layer of uncertainty, as under real environmental conditions the concentration of the parent compound may vary over time.

A better understanding of biotransformation in invertebrates, especially for new chemicals for which few data are available, is a necessary step towards better risk assessment of chemicals, especially their biological effects in invertebrates and at higher trophic levels. $k_{m}$ could thus be integrated into aquatic food web models or used to complete databases in other modeling frameworks, such as QSAR modeling (Arnot et al., 2008b). The biotransformation rate could also be integrated in toxicokinetic/toxicodynamic frameworks, such as DEBtox or GUTS models (Ockleford et al., 2018). In parallel, biological investigations such as research to develop biomarkers, could provide further valuable foundations for understanding and modeling biotransformation capacity in invertebrates.

\section{Acknowledgments}

This study was supported by the French Agency for Biodiversity. This work benefited from the French GDR "Aquatic Ecotoxicology" framework which aims at fostering stimulating scientific discussions and collaborations for more integrative approaches. The authors are grateful to Sandrine Charles (University of Lyon 1, CNRS, LBBE) for the help provided in solving equations of the model. The authors thank anonymous 
1 reviewers and to Glen McCulley for copyediting the manuscript. 


\section{References}

Arnot, J.A., Mackay, D., Bonnell, M., 2008. Estimating metabolic biotransformation rates in fish from laboratory data. Environ. Toxicol. Chem. 27, 341-351. https://doi.org/10.1897/07-310R.1

Arnot, J.A., Mackay, D., Parkerton, T.F., Bonnell, M., 2008. A database of fish biotransformation rates for organic chemicals. Environ. Toxicol. Chem. 27, 2263-2270. https://doi.org/10.1897/08-058.1

Ashauer, R., Caravatti, I., Hintermeister, A., Escher, B.I., 2010. Bioaccumulation kinetics of organic xenobiotic pollutants in the freshwater invertebrate Gammarus pulex modeled with prediction intervals. Environ. Toxicol. Chem. 29, 1625-1636. https://doi.org/10.1002/etc.175

Ashauer, R., Hintermeister, A., O'Connor, I., Elumelu, M., Hollender, J., Escher, B.I., 2012. Significance of xenobiotic metabolism for bioaccumulation kinetics of organic chemicals in Gammarus pulex. Environ. Sci. Technol. 46, 3498-3508. https://doi.org/10.1021/es204611h

Carrasco-Navarro, V., Jæger, I., Honkanen, J.O., Kukkonen, J.V.K., Carroll, J.L., Camus, L., 2015. Bioconcentration, biotransformation and elimination of pyrene in the arctic crustacean Gammarus setosus (Amphipoda) at two temperatures. Mar. Environ. Res. 110, 101-109. https://doi.org/10.1016/j.marenvres.2015.08.003

Chen, C.C., Kuo, D.T.F., 2018. Bioconcentration model for non-ionic, polar, and ionizable organic compounds in amphipod. Environ. Toxicol. Chem. 37, 13781386. https://doi.org/10.1002/etc.4081

E.P., E.C., 2000. Directive 2000/60/EC of the European Parliament and of the Council of 23 October 2000 establishing a framework for Community action in the field of water policy, in: Commission, E. (Ed.), 22 Dec. 2000 ed. Official Journal of the European Communities, pp. L327/321 - L327/372.

E.C., 2008. Directive 2008/105 of The European Parliament and of the Council on environmental quality standards in the field of water policy and amending Directive 2000/60/EC, pp. L 348/384-397.

EPA, 2006. Approaches for the Application of Physiologically Based Pharmacokinetic (PBPK) Models and Supporting Data in Risk Assessment (Final Report). Washington, D.C.

Fu, Q., Rösch, A., Fedrizzi, D., Vignet, C., Hollender, J., 2018. Bioaccumulation, Biotransformation, and Synergistic Effects of Binary Fungicide Mixtures in Hyalella azteca and Gammarus pulex: How Different/Similar are the Two Species? Environ. Sci. Technol. 52, 13491-13500. https://doi.org/10.1021/acs.est.8b04057 
Gelman, A., Carlin, J.B., Stern, H.S., Dunson, D.B., Vehtari, A., Rubin, D.B., 1995. Bayesian Data Analysis Third edition. New York, NY, USA.

Geweke, J., 1989. Bayesian Inference in Econometric Models using Monte Carlo Integration. Econometrica 57, 1317-1339.

Giessing, A.M.B., Mayer, L.M., Forbes, T.L., 2003. Synchronous fluorescence spectrometry of 1-hydroxypyrene: A rapid screening method for identification of $\mathrm{PAH}$ exposure in tissue from marine polychaetes. Mar. Environ. Res. 56, 599615. https://doi.org/10.1016/S0141-1136(03)00045-X

Jeon, J., Kurth, D., Ashauer, R., Hollender, J., 2013. Comparative toxicokinetics of organic micropollutants in freshwater crustaceans. Environ. Sci. Technol. 47, 8809-8817. https://doi.org/10.1021/es400833g

Katagi, T., 2010. Bioconcentration, bioaccumulation, and metabolism of pesticides in aquatic organisms. Rev. Environ. Contam. Toxicol. 204, 1-132.

Kuo, D.T.F., Chen, C.C., 2016. Deriving in vivo biotransformation rate constants and metabolite parent concentration factor/stable metabolite factor from bioaccumulation and bioconcentration experiments: An illustration with worm accumulation data. Environ. Toxicol. Chem. 35, 2903-2909. https://doi.org/10.1002/etc.3509

Lambert, P.C., Sutton, A.J., Burton, P.R., Abrams, K.R., Jones, D.R., 2005. How vague is vague? A simulation study of the impact of the use of vague prior distributions in MCMC using WinBUGS. Stat. Med. 24, 2401-2428. https://doi.org/10.1002/sim.2112

Livingstone, D.R., 1994. Recent developments in marine invertebrate organic xenobiotic metabolism. Toxicol. Ecotoxicological News 1, 88-94.

Livingstone, D.R., 1998. The fate of organic xenobiotics in aquatic ecosystems: quantitative and qualitative differences in biotransformation by invertebrates and fish. Comp. Biochem. Physiol. Part A Mol. Integr. Physiol. 120, 43-49.

MacKay, D., Fraser, A., 2000. Bioaccumulation of persistent organic chemicals: Mechanisms and models. Environ. Pollut. 110, 375-391. https://doi.org/10.1016/S0269-7491(00)00162-7

Mäenpää, K., Leppänen, M.T., Kukkonen, J.V.K., 2009. Sublethal toxicity and biotransformation of pyrene in Lumbriculus variegatus (Oligochaeta). Sci. Total Environ. 407, 2666-2672. https://doi.org/10.1016/j.scitotenv.2009.01.019

Miller, T.H., Bury, N.R., Owen, S.F., Barron, L.P., 2017. Uptake, biotransformation and elimination of selected pharmaceuticals in a freshwater invertebrate measured using liquid chromatography tandem mass spectrometry. Chemosphere 183, 389-400. https://doi.org/10.1016/j.chemosphere.2017.05.083 
Morrison, H.A., Gobas, F.A.P.C., Lazar, R., Haffner, G.D., 1996. Development and verification of a bioaccumulation model for organic contaminants in benthic invertebrates. Environ. Sci. Technol. 30, 3377-3384. https://doi.org/10.1021/es960280b

Nichols, J.W., Fitzsimmons, P.N., Burkhard, L.P., 2007. In vitro-in vivo extrapolation of quantitative hepatic biotransformation data for fish. II. Modeled effects on chemical bioaccumulation. Environ. Toxicol. Chem. 26, 1304-1319. https://doi.org/10.1897/06-259R.1

Ockleford, C., Adriaanse, P., Berny, P., Brock, T., Duquesne, S., Grilli, S., Hernandez-Jerez, A.F., Bennekou, S.H., Klein, M., Kuhl, T., Laskowski, R., Machera, K., Pelkonen, O., Pieper, S., Smith, R.H., Stemmer, M., Sundh, I., Tiktak, A., Topping, C.J., Wolterink, G., Cedergreen, N., Charles, S., Focks, A., Reed, M., Arena, M., Ippolito, A., Byers, H., Teodorovic, I., 2018. Scientific Opinion on the state of the art of Toxicokinetic/Toxicodynamic (TKTD) effect models for regulatory risk assessment of pesticides for aquatic organisms. EFSA J. 16. https://doi.org/10.2903/j.efsa.2018.5377

Plummer, M. 2019. rjags: Bayesian Graphical Models using MCMC. R package version 4-10. https://CRAN.R-project.org/package=rjags

R Core Team. 2020. R: A language and environment for statistical computing. $R$ Foundation for Statistical Computing, Vienna, Austria. https://www.R-project.org/

Raftery, A.E., Lewis, S.M., 1992. [Practical Markov chain Monte Carlo]: Comment: one long run with diagnostics: implementation strategies for Markov chain Monte Carlo. Stat. Sci. 7, 493-497.

Ratier, A., Lopes, C., Labadie, P., Budzinski, H., Delorme, N., Quéau, H., Peluhet, L., Geffard, O., Babut, M., 2019. A Bayesian framework for estimating parameters of a generic toxicokinetic model for the bioaccumulation of organic chemicals by benthic invertebrates: Proof of concept with PCB153 and two freshwater species. Ecotoxicol. Environ. Saf. 180, 33-42. https://doi.org/10.1016/j.ecoenv.2019.04.080

Richards, R.G., Chaloupka, M., 2009. Temperature-dependent bioaccumulation of copper in an estuarine oyster. Sci. Total Environ. 407, 5901-5906. https://doi.org/10.1016/j.scitotenv.2009.07.039

Rösch, A., Anliker, S., Hollender, J., 2016. How Biotransformation Influences Toxicokinetics of Azole Fungicides in the Aquatic Invertebrate Gammarus pulex. Environ. Sci. Technol. 50, 7175-7188. https://doi.org/10.1021/acs.est.6b01301

Schuler, L.J., Wheeler, M., Bailer, A.J., Lydy, M.J., 2003. Toxicokinetics of sedimentsorbed benzo[a]pyrene and hexachlorobiphenyl using the freshwater invertebrates Hyalella azteca, Chironomus tentans, and Lumbriculus variegatus. Environ. Toxicol. Chem. 22, 439-449. https://doi.org/10.1002/etc.5620220227 
1 U.S. EPA IRIS, 2017. Toxicological Review of Benzo [a] pyrene [CASRN 50-32-8]

2 (Final Report). Washington, DC, EPA/635/R-17/003F.

3 Van der Linde, A., Jan Hendriks, A., Sijm, D.T.H.M., 2001. Estimating 4 biotransformation rate constants of organic chemicals from modeled and 5 measured elimination rates. Chemosphere 44, 423-435.

6 https://doi.org/10.1016/S0045-6535(00)00213-7 